\title{
Study on Risk Management for Global Sourcing
}

\author{
Xi Zhang \\ School of Mechanical engineering \\ Shanghai Jiao Tong University \\ Shanghai, China \\ shanexixi@163.com
}

\section{Chenyan $\mathrm{Xu}$}

School of Mechanical engineering Shanghai Jiao Tong University

Shanghai, China luckyxcy@163.com

\author{
Rui Miao \\ School of Mechanical engineering \\ Shanghai Jiao Tong University \\ Shanghai, China \\ miaorui@sjtu.edu.cn
}

Liya Wang

School of Mechanical engineering . Shanghai Jiao Tong University

Shanghai, China wangliya@sjtu.edu.cn

\author{
Xiaoxu Deng \\ Department of Physics and Astronomy \\ Shanghai Jiao Tong University \\ Shanghai, China \\ xxdeng@sjtu.edu.cn
}

\begin{abstract}
Being along with globalization development and acceleration, big challenges are in front of all the enterprises. So more and more companies are doing global sourcing to reach cost saving and be more competitive. Today China is not only the center of manufacture globally, as well as the center of global sourcing. Whereas with the big procurement volume and speedy developing, how to secure the smooth execution of global sourcing project and how to decrease the risk as much as possible are quite essential concerns for multinational corporations.
\end{abstract}

Keywords_Globalization development; Sourcing; Risk management; Gate Review

\section{INTRODUCTION}

Along with global economic integration, the market competition becomes more and more fierce. To minimize the sourcing cost and become more competitive in the market, IPO, which means International Purchase Office, is just the new popular sourcing mode for multinational companies[1]. Fig.1 illustrates the normal working flow chart for a typical IPO in China[2]. Whereas opportunities always are linked to risks. Global sourcing as well has lots of risks.

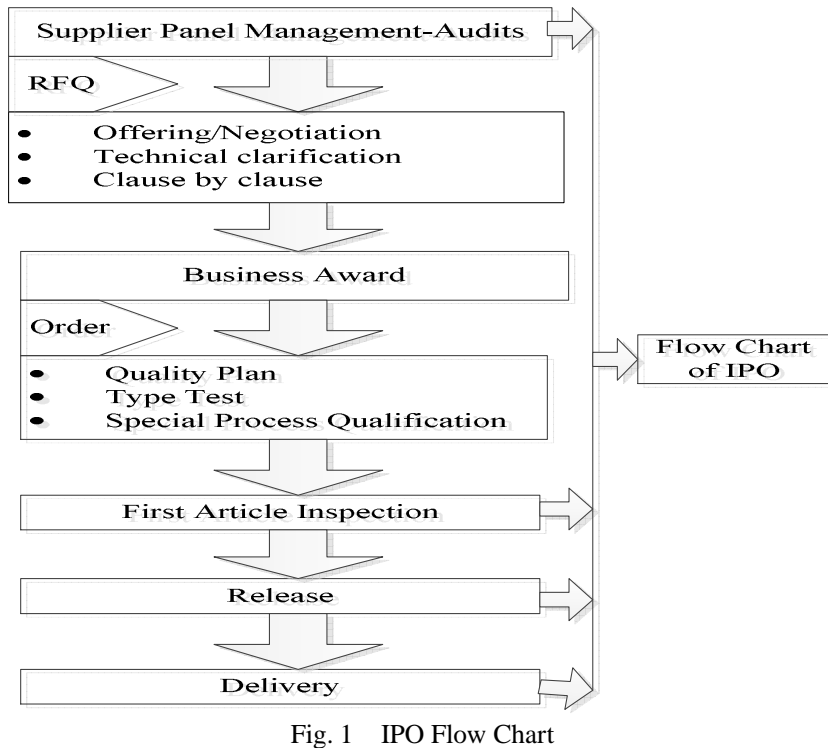

A. Risk Identification in IPO Global Sourcing

Sourcing locates the beginning of whole supply chain in enterprise operation. If any company wants to maximize the profit, to decrease and optimize the cost is the most direct approach. There into $45.3 \%$ comes from raw materials, which is the most proportion. So sourcing department plays a quite important role in a company. Any deviation in sourcing process will impact the final profit target hugely[3].

However, because of uncertainty and unforeseen factors, during sourcing process, all kinds of risks can happen, like risk in sourcing plan which mainly caused by inappropriate 
management that leads to sourcing plan, target, quality and delivery are bad, especially for global sourcing[4]. Normally during sourcing activity in IPO we will have the following risks:

(1)Quality risk: big gap between local supplier's level and European requirements in terms of quality control and management[5]. The main risks include how to secure the local supplier's quality level to meet European requirement, how to take quick response in case of quality problem happened in Europe because of the long distance between China and Europe, as well as how to control the quality cost, etc[6].

(2)Technical risk: Considering the long distance, how to secure the technical inputs from Europe are completed and accurate, how to evaluate the technical capability of Chinese suppliers in Europe, in case of any technical modifications during project implementation, how to communicate with Chinese suppliers efficiently and effectively, how to secure the out-source products have good and reliable quality, etc[7].

(3)Commercial risk: Due to these export projects, how to minimize the risk on exchange rate fluctuation[8], how to control the price increase caused by raw material and labor cost increase, etc[9].

(4)Planning risk: many risks exist during transportation because of the long distance.

Moreover, the culture difference between China and Europe, management experience, way of thinking, way of working, resources of human being etc are all the aspects we should consider as risks[10]. Hereinafter we can consolidate main risks in IPO global sourcing activity into Table 1 as below.
Table 1 Risk Identification \& Evaluation

\begin{tabular}{|c|c|c|c|c|c|}
\hline \multicolumn{2}{|r|}{ Risk Identification } & \multicolumn{4}{|c|}{ Risk Evaluation } \\
\hline Type & Sympton & Possibility & Severity & $\begin{array}{l}\text { Risk } \\
\text { Index }\end{array}$ & Priority \\
\hline Quality risk & Supplier qualification & 5 & 10 & 50 & 2 \\
\hline Quality risk & $\begin{array}{c}\text { Product quality can not meet } \\
\text { european requirement }\end{array}$ & 5 & 10 & 50 & 2 \\
\hline Quality risk & How to deal with NCR in europe & 3 & 7 & 21 & 9 \\
\hline Technical risk & $\begin{array}{l}\text { Technical input from europe is } \\
\text { complete or not }\end{array}$ & 7 & 10 & 70 & 1 \\
\hline Technical risk & $\begin{array}{l}\text { Supplier's technical level can not } \\
\text { meet european requirement }\end{array}$ & 5 & 10 & 50 & 2 \\
\hline Technical risk & $\begin{array}{l}\text { How to communicate for technical } \\
\text { modification }\end{array}$ & l & 7 & 49 & 5 \\
\hline Technical risk & $\begin{array}{l}\text { Process and out-sourceparts quality } \\
\text { control }\end{array}$ & 5 & 7 & 35 & 7 \\
\hline Commercial risk & Exchange rate fluctuation & 5 & 7 & 35 & 7 \\
\hline Commercial risk & $\begin{array}{l}\text { Price increase caused by raw } \\
\text { material cost increase }\end{array}$ & 5 & 4 & 20 & 10 \\
\hline Planning risk & Long transportation & 7 & 7 & 49 & 5 \\
\hline Management risk & $\begin{array}{l}\text { Supplier's management way and } \\
\text { resources }\end{array}$ & 3 & 4 & 12 & 11 \\
\hline
\end{tabular}

Note: Possibility (1) are: 1-very low, 3-low, 5-medium,7-high, 9-very high Severity (2) are: 1-light, 4-medium, 7-critical, 10-high critical (3): Risk Index=Possibility*Severity

As shown in Table 1, those are the most risks for IPO activity of global sourcing in China, and they are also classified as per the possibility of risk and its severity of consequences, as well are sorted as above shown[11].

However risk exist anywhere and anytime due to its uncertainty. Considering the limited budget and resources, it's impossible to take actions to remove all the risks, neither it's necessary. Normally we only pay more attention to the major risks whose index are higher, as well to define action plan to prevent these risks[12]. The matrix shown in Fig. 2 is one kind of rules. According to this rule, we can clear classify which risk needs to be taken care of. 


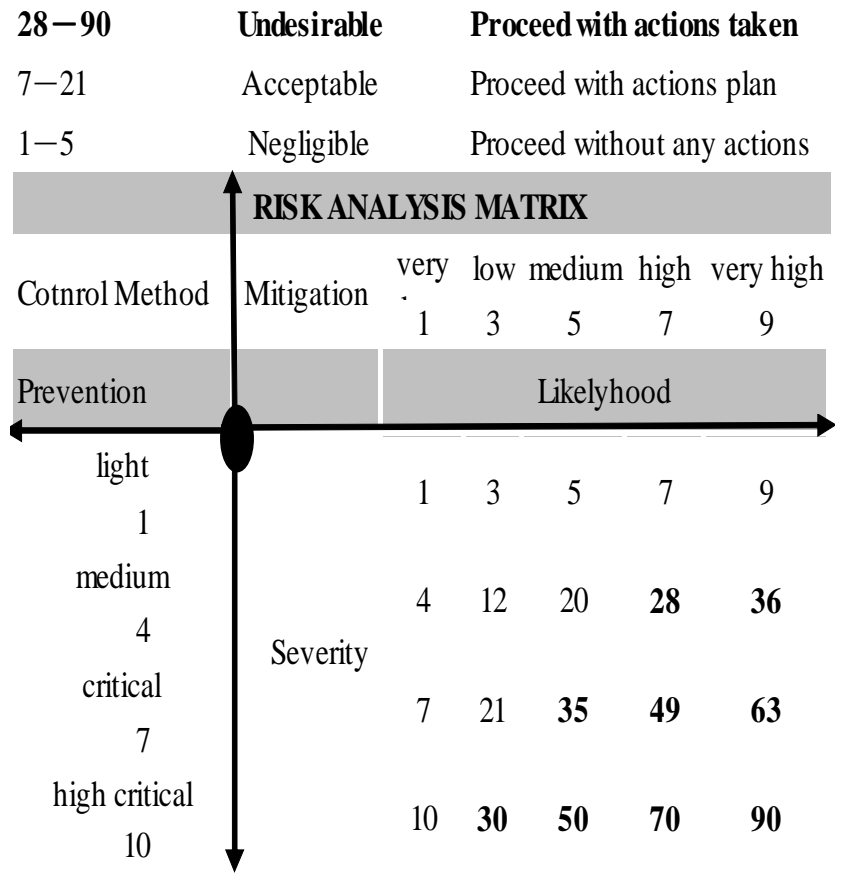

Fig. 2 Risk Analysis Matrix

After this classification, how to remove these risks, especially the major risks? Although we have systematic supplier management process to do daily monitoring and following, here I still want to introduce a new approach - Gate review, as an auxiliary tool to improve the risk management in IPO global sourcing projects.

\section{GATE REVIEW}

\section{A. Definition \& Process}

Gate review, in project management, is used to emphasize the importance and necessarily on each milestone[13]. Only if the result of Gate Review is GO, the process can move on. The main purpose of Gate Review is to identify the risks as early as possible and remove them before going to further step. Fig. 3 is the definition of Gate Review. From this chart, we can see Gate Review is running through the whole project implementation.

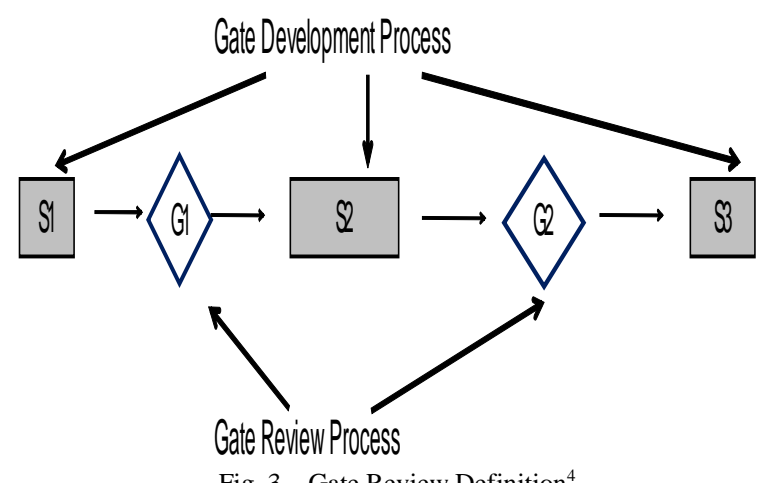

Fig. 3 Gate Review Definition ${ }^{4}$
Fig. 4 \& 5 illustrate the working process of Gate Review. When you do Gate Review, as per different results, different actions need to be taken accordingly, such as continue, redirect, hold or kill.

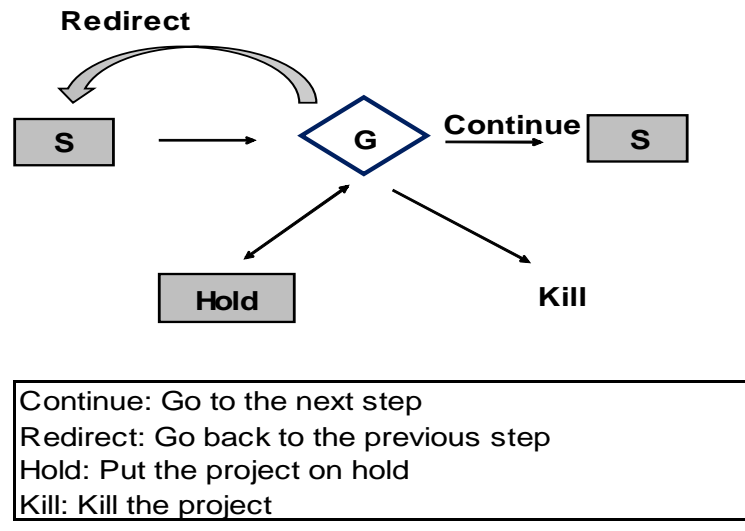

Fig. 4 Gate Review Process ${ }^{4}$

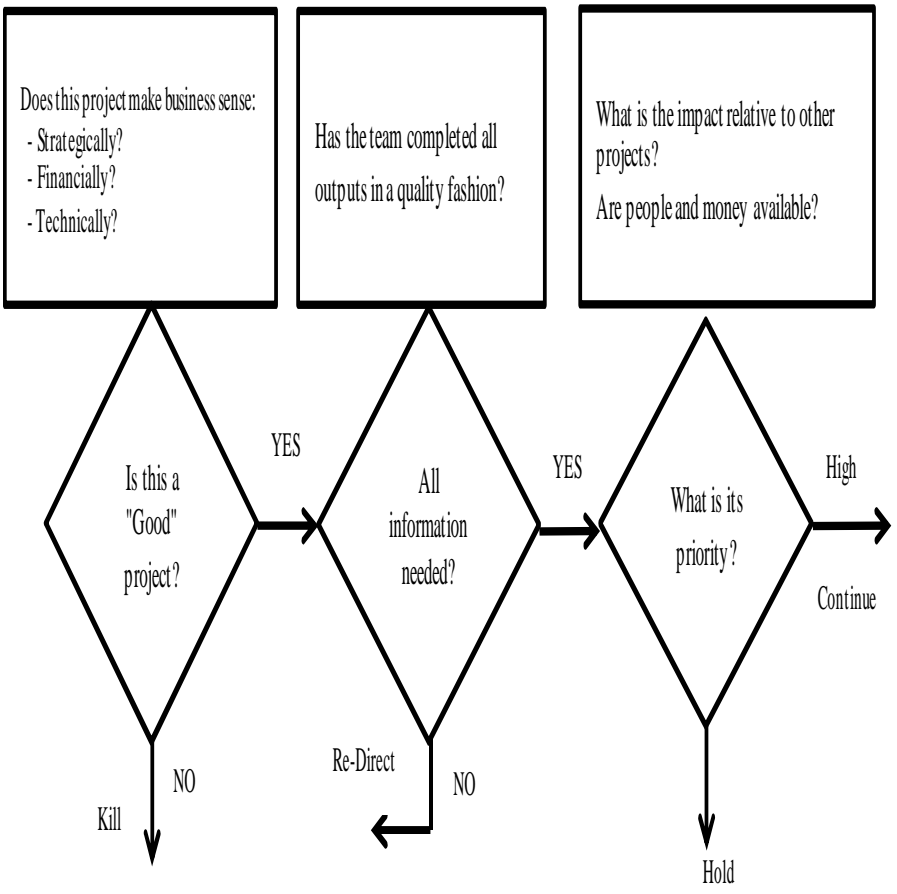

Fig.5 Three-Step Decision Process ${ }^{4}$

General speaking, on each key milestone of project implementation, using Gate Review is to review all the points, to check whether there're some key open points which will lead to more risky in the further steps, then to define further actions. The target is to minimize the risk at the earliest stage.

\section{B. Application in IPO Global Sourcing}

\section{1) Milestone definition}

As per saying above, Gate Review should be done in each key step, that means to define milestones of a project is the first job to be done. So according to the working flow of IPO 
global sourcing, we can easily define the following steps as the key milestones which are shown in Fig. 6.

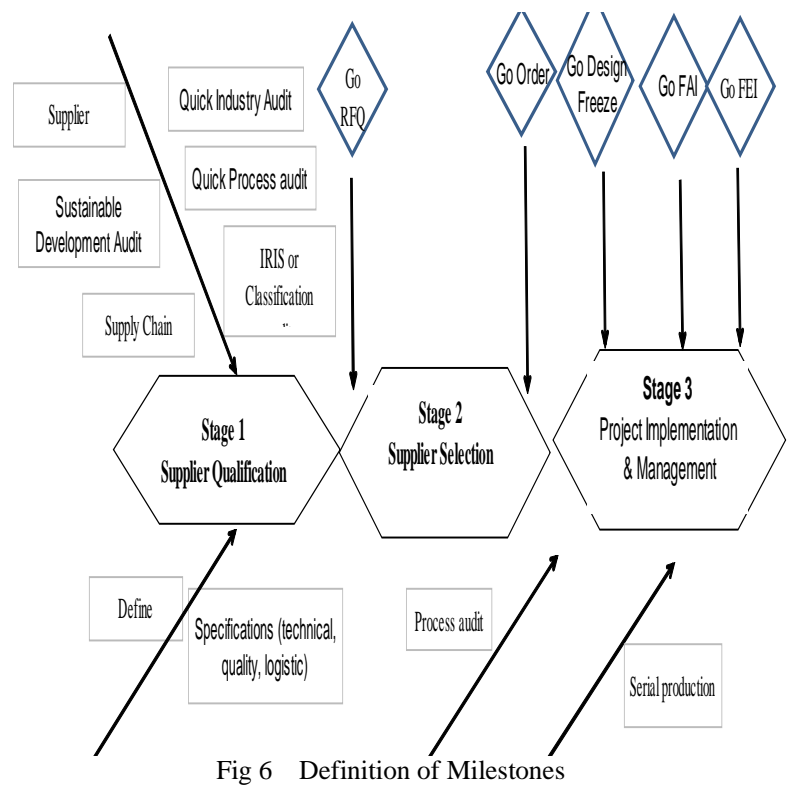

From the above Fig., we can find out the key milestones include: Go RFQ (Request of Quotation). Go Order, Go Design Freeze, Go FAI(First Article Inspection), GO FEI(First Equipment Inspection).

\section{2) Application of Gate Review}

After defining the key milestones, it's turn to organize Gate Review meeting, It is including the participants to be invited, contents to be discussed, action plan to be defined after Gate review meeting, etc. Hereinafter we will take Go RFQ as an example to illustrate this approach.

Considering the pre-inputs of IPO global sourcing activity is from the headquarter in Europe, either technical data, purchasing information, or quality, logistic data are important to be reviewed by IPO before launching the RFQ to Chinese suppliers. Therefore, Gate review is a good and appropriate tool to be used in this situation.

The meeting can be organized as below:

\section{(1)Meeting holder: IPO sourcing engineer}

(2)Participants: IPO sourcing engineer, technical engineer, quality engineer, logistic engineer

(3)First meeting time: within 1 week after sourcing engineer receive the RFQ data from Europe.

(4)Reviewed contents: As per check list, quality, technical, purchasing, logistic aspects should be reviewed, such as whether the quoted suppliers are panel suppliers or not, drawings are complete and right or not, technical/quality/logistic specifications are provided and clear or not, package specification is included or not, supply scope and BOM (Bill Of Material) are clarified or not, capacity of suppliers is evaluated or not, Non-Disclosure agreement is signed by supplier or not, etc.
(5)Meeting results and action plan: a team decision should be taken by all participants. If the conclusion is GO, sourcing engineer will launch the RFQ to Chinese suppliers. If the conclusion is NO GO, detailed action plan should be defined with each action owner and due date. After the meeting, each owner should contact Europe to find out the solution before the due date. Meanwhile, a second Go RFQ Gate review to be booked by the team. Only if the final result is GO, the Gate review will close and the process can move forward to the next step. Table 2 is one of the template which can be used for Go RFQ Gate Review.

Table 2 Gate Review - Go FRQ

GO RFQ CHECK LIST

\begin{tabular}{|c|c|c|c|}
\hline Project: & & Supplier/Product: & \\
\hline Attendees & & Owner/Date: & \\
\hline Owner & $\begin{array}{l}\text { Question / } \\
\text { Item }\end{array}$ & Instructions & $\begin{array}{c}\text { ATSL } \\
\text { Validation }\end{array}$ \\
\hline Buyer & $\begin{array}{l}\text { Drawing } \\
\text { package are } \\
\text { available? }\end{array}$ & $\begin{array}{l}\text { If drawing not in } \\
\text { English, translation list } \\
\text { will be made before go } \\
\text { order. The GO RFQ will } \\
\text { be No GO but the RFQ } \\
\text { will send to supplier } \\
\text { with agreement of } \\
\text { sourcing, quality and } \\
\text { supply chain. }\end{array}$ & \\
\hline Technical & $\begin{array}{l}\text { The drawings } \\
\text { can be used to } \\
\text { quote? }\end{array}$ & & \\
\hline Buyer & $\begin{array}{l}\text { Technical } \\
\text { Specifications } \\
\text { are available? }\end{array}$ & $\begin{array}{l}\text { If specification not in } \\
\text { English, buyer will ask } \\
\text { site to translate. The GO } \\
\text { RFQ will be No GO but } \\
\text { the RFQ will send to } \\
\text { supplier with agreement } \\
\text { of sourcing, quality and } \\
\text { supply chain. }\end{array}$ & \\
\hline $\mathrm{SC}$ & $\begin{array}{l}\text { Packaging } \\
\text { Specification is } \\
\text { available } \\
\text { (Kitting, box...) }\end{array}$ & $\begin{array}{l}\text { If Pack. Spec.n is not in } \\
\text { the RFQ package. } \\
\text { 1) SC team will ask } \\
\text { ATSA to provide it in } \\
24 \text { hours. } \\
\text { 2-1) If received in } 24 \\
\text { hours, SC team will } \\
\text { send it to buyer to } \\
\text { complete the RFQ } \\
\text { package. Go RFQ } \\
\text { 2-2) If not, Go RFQ. SC } \\
\text { will get best proposal } \\
\text { from Supplier a }\end{array}$ & \\
\hline $\mathrm{SC}$ & $\begin{array}{l}\text { Total Quantity } \\
\text { (BOM) + Batch } \\
\text { size are } \\
\text { available? }\end{array}$ & $\begin{array}{l}\text { Total Quantity (BOM)+ } \\
\text { Production Rhythm } \\
\text { should be in Logistics } \\
\text { specification } \\
\text { If batch size not } \\
\text { communicated, SC team } \\
\text { will propose the batch } \\
\text { size to complete the } \\
\text { RFQ package in } 24 \\
\text { hours. GO RFQ }\end{array}$ & \\
\hline Buyer & $\begin{array}{l}\text { SQS is } \\
\text { available? }\end{array}$ & $\begin{array}{l}\text { If SQS is not available } \\
\text { after requirement of } \\
\text { buyer, ATSL standard } \\
\text { SQS will be used for }\end{array}$ & \\
\hline
\end{tabular}




\begin{tabular}{|c|c|c|c|}
\hline & & $\begin{array}{l}\text { RFQ. Quality will send } \\
\text { the standard SQS in } 24 \\
\text { hours. }\end{array}$ & \\
\hline Buyer & $\begin{array}{l}\text { Supplier is in } \\
\text { Panel? }\end{array}$ & & \\
\hline Technical & $\begin{array}{l}\text { Scope of } \\
\text { supplier is } \\
\text { consistented } \\
\text { with RFQ? }\end{array}$ & & \\
\hline Technical & $\begin{array}{l}\text { Supplier has } \\
\text { the capable } \\
\text { manufacturing } \\
\text { process to } \\
\text { produce the } \\
\text { part? }\end{array}$ & & \\
\hline \multirow[t]{2}{*}{ Buyer } & $\begin{array}{l}\text { Is the NDA } \\
\text { signed by } \\
\text { supplier or not? }\end{array}$ & & \\
\hline & $\begin{array}{l}\text { General } \\
\text { comments: }\end{array}$ & $\begin{array}{l}\text { Indirect Sourcing should } \\
\text { give buyer the transport } \\
\text { cost to finilise the } \\
\text { transport cost based on } \\
\text { supplier's packaging } \\
\text { solution. }\end{array}$ & \\
\hline DECISION : & & Comments & \\
\hline \multirow[b]{2}{*}{ Action Plan } & Action & Responsible & Target Date \\
\hline & & & \\
\hline
\end{tabular}

With the same logic, we can spread the process to all key steps, such as Go Order, Go Design Freeze, Go FAI, Go FEI etc. Appropriate and similar templates can be defined as well. After application of this tool, with some analysis, you may find out the risk level at each stage improves a lot due to this new added action, that means this approach works well.

\section{CONCLUSION}

Along with the integration of global economics, IPO global sourcing now is playing more and more important role in sourcing modes for multinational companies. How to control the risks inside is the major point for all, which possibly determines the final win or lose directly. So using Gate review, from a certain extent, can help on this point, which is worth to be promoted.

\section{ACKNOWLEDGEMENTS}

The authors gratefully acknowledge the financial support of the national natural science foundation, China (No.70932004) and the sixth innovation practice program of Shanghai (IAP6021).

\section{REFERENCES}

[1] Jeffery K. Pinto, "Project Management: Achieving Competitive Advantage", China Machine Press, 2007, in press

[2] "ATSL Sourcing Procedure", 2010, unpublished

[3] Trent, R. J. \& Monczka, R. M, "Understanding integrated global sourcing [J]", International Journal of Physical Distribution \& Logistics Management, 2003, 33 (7): 607- 629, in press

[4] Zsidisin, G.. A. \& Ellram, L. M, "An agency investigation of supply risk management[J]", Journal of Supply Chain Management, 2003(3), in press

[5] Li Jinhai, "Project Quality Management", Nankai University Press, 2006 , in press

[6] “AT Supplier Quality Requirement”, 2010, unpublished
[7] Wu Shourong, "Project Sourcing Management", China Machine Press, 2004 , in press

[8] Liu Wei, "Risk Analysis in Global Sourcing", Economic Administration, 2008 , in press

[9] Chen Yan, "International Sourcing Risk Management", CO-Operative Economy \& Science, 2008, in press

[10] Li Lin, "Multinational Company's Supplier Evaluation and Selection in Global Sourcing", Shanghai Enterprise, 2008, in press

[11] Xiao Lei \& Wang Tie, "Risk Quantitative Measurement Method of Sourcing", Economic Research Journal, 2010, in press

[12] Cao Yujie, "Sourcing Risk Management Strategy based on Risk Matrix", Guide to Business, 2011, in press

[13] Mark Polczynski, "Stage Gate Review Process" www.doc88.com, 2010 , in press 